\title{
Effect of the kinetic variables and postural stability between bilateral in lower limbs by the Oreum trekking exercise: asymmetric index
}

\author{
Che-Cheong Ryew, Seung-Hyun Hyun* \\ Department of Kinesiology, College of Natural Science, Jeju National University, Jeju, Korea
}

This study aimed to analyze an effect of the kinetic variables and postural stability between bilateral in lower limbs by participation of Oreum trekking exercise program and subjects participated were composed of adult male and female subjects $(n=14)$ of 20 s. Experiment was performed with the drop landing which can evaluate postural stability and kinetic variables between bilateral in lower limbs. peak vertical force (PVF) value showed significant difference with the less in case of post than before participation of Oreum trekking exercise. Also PVF of bilateral in lower limbs did not showed significant difference, and too the effect of interaction. vertical stability index (VSI) and dynamic postural stability index (DPSI) showed significant difference with improvement of postural stability by Oreum trekking, but did not between bilateral in the limbs. Particularly the result of one-way analysis of variance due to VSI's effect of interaction, showed the more influence on the improvement of postural stability in left leg after participation of Oreum trekking exercise. When consideration the above, the analysis result on asymmetric index of bilateral in lower limbs showed more symmetric pattern in post than before participation of Oreum trekking exercise program.

Keywords: Oreum, Trekking, Asymmetric index, Drop landing, Postural stability, Required coefficient of friction

\section{INTRODUCTION}

In contrast to all the other mammals, human sustains bipedal stance and gait as means of their normal posture and locomotion. As a consequence, humans are required to balance against multiple segments with a center of mass (COM) of high position over a narrow base of support (Taube et al., 2008). Thus bipedal walking which give less impact and stress against whole body has been used as a means of rehabilitation, prescription and therapy for normal or patient of obesity, diabetics, old-age and pulmonary (Choi et al., 2010; Kim, 2007; Lee and Kim, 2010).

Locomotion was performed on not only level but also various situations of ground of which Jeju's Oreum is suitable for trekking course due to low level of altitude and no hard work of shuttle distance. Particularly environmental condition of ground surface of Oreum was made up various of conditions, irregular pat- tern like scoria, soils, grass land, rock, valley, stair-way, inclined load, etc. Also participants of Oreum trekking can observe various kinds of animal and botany and experience unstable ground condition.

Effect of walking exercise show somewhat difference according to ground conditions, but adaptability of balancing factors on the ground enhanced a sense of proprioceptor and reduction of falling injuries by condition of unstable ground (Eisen et al., 2010; Schilling et al., 2009). Balancing training of posture on the unstable ground condition has been used as purpose of rehabilitation for improvement of posture control ability on the injuries of ankle and knee joint (Taube et al., 2008), and reported positive effect on the posture control against direction of medial and lateral and anterior-posterior (AP) for normal adult (Hoffman and Payne, 1995). That is, the function of postural control was depended on the somatic sense from foot-part which contact with supporting
${ }^{\star}$ Corresponding author: Seung-Hyun Hyun iD http://orcid.org/0000-0001-6348-6413 Department of Kinesiology, College of Natural Science, Jeju National University, 102 Jejudaehak-ro, Jeju 63243, Korea

Tel: +82-64-754-2273, Fax: +82-64-757-1752, E-mail: hshyun0306@jejunu.ac.kr Received: June 14, 2016 / Accepted: July 23, 2016
This is an Open Access article distributed under the terms of the Creative Commons Attribution Non-Commercial License (http://creativecommons.org/licenses/by-nc/4.0/) which permits unrestricted non-commercial use, distribution, and reproduction in any medium, provided the original work is properly cited. 
plane (Shumway-Cook and Woollacott, 2007), which is necessary more enhanced interaction function in terms of central nerve and various muscles for stable movement (Sadeghi et al., 2000).

But it was reported that walking on rough or descending supporting surface can cause higher possibility of injury by irregular walking due to increase of strength and moment (Knapik et al., 1996; Kuster et al., 1995).

When summarization of the previous studies, the conclusions on movement effects from unstable supporting surface was different each other and particularly was performed during mostly short period. Oreum trekking, which was performed for long period, is necessary to analyze the effect of exercise quantitatively. Therefore the aim of the study was to provide quantitative materials for exercise and rehabilitation with analysis of the effects on the kinetic variables and postural stability between bilateral in lower limbs with asymmetric index.

\section{MATERIALS AND METHODS}

\section{Subject}

Subjects participated was consisted of total 14 of adult male and female (mean age, $21.64 \pm 2.37 \mathrm{yr}$; mean heights, 168.60 \pm $9.04 \mathrm{~cm}$; mean weights, $62.88 \pm 9.61 \mathrm{~kg}$ ). They was lectured about the aim of study explained before experiment and recruited subjects agreed voluntarily on participation of Oreum trekking exercise program and experiment.

\section{Experimental procedure}

The Oreum trekking was performed with ascending and descending courses with alternative stair or incline lane continuously but its height and incline angle of stair was composed of irregular pattern. When consideration of these conditions of courses, the experiment was performed with the drop landing which can evaluate postural stability and kinetic variables between bilateral of lower limbs.

Each subject, after enough warm-up exercise, performed on the order of bilateral, right and left drop landing on the height of 30$\mathrm{cm}$ wooden platform. Oreum trekking during total 5 day included the first day performed the drop landing was performed with distance of $15-20 \mathrm{~km} / 3.5 \mathrm{hr}$ a day (10-min rest/50-min trekking, respectively).

Then, mean altitude of Oreums (SemiyangOreum, Hallaecoforest and JeolmulOreum, Saryeoniforest and RedOreum, JeolmulOreum and GeochinOreum, SaraOreum) was 756.68 $\pm 321.22 \mathrm{~m}$ and $4-5 \mathrm{~km} / \mathrm{hr}$ of moved velocity (moved distance divided with total elapsed time). Like this, after performed for 5 days of Oreum trekking, performed the experiment of drop landing at the 8th day after individual rest for 2 days with consideration of subject's fatigue.

\section{Analysis and process of data}

The dynamic postural stability index (DPSI: ML, medial lateral; AP, anterior posterior; SI, stability index; V, vertical) was determined by the procedures described by Wikstrom et al. (2005) and Hyun et al. (2014).

$$
\begin{gathered}
\text { MLSI }=\sqrt{\sum\left(0-\mathrm{Fx}_{\max }\right)^{2} / \text { samples }}, \quad \text { APSI }=\sqrt{\sum\left(0-\mathrm{Fy}_{\max }\right)^{2} / \text { samples }} \\
\text { VSI }=\sqrt{\sum\left(0-\mathrm{Fz}_{\max }\right)^{2} / \text { samples }}, \quad \text { DPSI }=\mathrm{MLSI}+\mathrm{APSI}+\mathrm{VSI}
\end{gathered}
$$

Required coefficient of friction (RCOF) was defined as value of ML ground reaction force (GRF) and AP GRF divided by peak vertical force (PVF), RCOF in ML direction and RCOF in AP direction was in the same line with (Asaka et al., 2002; Burnfield and Powers, 2007; Cooper et al., 2008).

$$
\mathrm{RCOF}=\frac{\sqrt{(\mathrm{MLGRF})^{2}+(\mathrm{APGRF})^{2}}}{\mathrm{PVF}}
$$

The symmetry index was determined by the procedures described by Barber et al. (1990).

$$
\frac{\text { Nondominant leg }}{\text { Domanant leg }} \times 100
$$

Two-way analysis of variance was performed on variance of experiment of Oreum trekking (pre, post) and bilateral (right, left), then, when showing the effect of interaction, interpreted with one-way analysis of variance on significance level of $P<0.05$.

\section{RESULTS}

As shown in Table 1, PVF value showed significant difference with the less in case of post than before participation of Oreum trekking exercise program $(P<0.05)$. Also, PVF of bilateral in lower limbs did not showed significant difference $(P>0.05)$, and too the effect of interaction $(P>0.05)$.

VSI and DPSI showed significant difference with improvement of postural stability by Oreum trekking $(P<0.05)$, but did not between bilateral in the limbs $(P>0.05)$. Particularly the result of one-way analysis of variance due to VSI's effect of interaction, showed the more influence on the improvement of postural stability of left leg after participation of Oreum trekking exercise $(F=4.094, P<0.05)$.

The analysis result on asymmetric index of bilateral in lower 
Table 1. Kinetic variables, asymmetrics, and postural stability by Oreum trekking exercise program

\begin{tabular}{|c|c|c|c|c|c|c|c|c|}
\hline \multirow{2}{*}{ Section } & \multirow{2}{*}{ Landing leg } & \multicolumn{2}{|c|}{ Test } & \multirow{2}{*}{ Total average } & \multirow{2}{*}{ Asymmetrics (\%) } & \multirow{2}{*}{ Source } & \multirow{2}{*}{$F$} & \multirow{2}{*}{$P$-value } \\
\hline & & Pretest & Posttest & & & & & \\
\hline \multirow[t]{3}{*}{ Peak vertical force (N/BW) } & Right & $5.73 \pm 1.09$ & $4.98 \pm 0.67$ & $5.53 \pm 0.97$ & $13.21 \pm 11.48$ & $\mathrm{~L}$ & 0.337 & 0.564 \\
\hline & Left & $5.33 \pm 0.81$ & $5.12 \pm 0.82$ & $5.22 \pm 0.81$ & $9.53 \pm 7.76$ & $\mathrm{~T}$ & 4.307 & $0.043^{*}$ \\
\hline & Total average & $5.53 \pm 0.97$ & $5.05 \pm 0.74$ & $5.29 \pm 0.88$ & - & $L \times T$ & 1.415 & 0.240 \\
\hline \multirow[t]{3}{*}{ Loading rate (N/BW/sec) } & Right & $122.38 \pm 39.01$ & $107.10 \pm 26.01$ & $114.74 \pm 33.45$ & $21.03 \pm 14.11$ & $\mathrm{~L}$ & 0.136 & 0.714 \\
\hline & Left & $113.04 \pm 25.97$ & $110.41 \pm 29.81$ & $111.72 \pm 27.47$ & $20.76 \pm 15.42$ & $\mathrm{~T}$ & 1.193 & 0.280 \\
\hline & Total average & $117.71 \pm 32.86$ & $108.76 \pm 27.51$ & $113.23 \pm 30.36$ & - & $\mathrm{L} \times \mathrm{T}$ & 0.596 & 0.444 \\
\hline \multirow[t]{3}{*}{$\mathrm{MLSI}$} & Right & $1.02 \pm 0.42$ & $0.97 \pm 0.38$ & $0.99 \pm 0.39$ & $30.85 \pm 26.20$ & L & 0.247 & 0.621 \\
\hline & Left & $1.06 \pm 0.53$ & $0.80 \pm 0.51$ & $0.93 \pm 0.53$ & $43.51 \pm 34.91$ & $\mathrm{~T}$ & 1.542 & 0.220 \\
\hline & Total average & $1.04 \pm 0.47$ & $0.88 \pm 0.45$ & $0.96 \pm 0.46$ & - & $\mathrm{L} \times \mathrm{T}$ & 0.682 & 0.413 \\
\hline \multirow[t]{3}{*}{ APSI } & Right & $3.36 \pm 0.81$ & $3.31 \pm 0.87$ & $3.33 \pm 0.83$ & $28.95 \pm 25.86$ & $\mathrm{~L}$ & 0.926 & 0.340 \\
\hline & Left & $3.87 \pm 0.80$ & $3.22 \pm 0.80$ & $3.55 \pm 0.85$ & $22.64 \pm 15.51$ & $\mathrm{~T}$ & 2.485 & 0.121 \\
\hline & Total average & $3.61 \pm 0.83$ & $3.27 \pm 0.82$ & $3.44 \pm 0.84$ & - & $\mathrm{L} \times \mathrm{T}$ & 1.785 & 0.187 \\
\hline \multirow[t]{3}{*}{ VSI } & Right & $23.85 \pm 6.28$ & $22.60 \pm 6.28$ & $23.22 \pm 6.20$ & $24.26 \pm 21.50$ & $\mathrm{~L}$ & 0.441 & 0.510 \\
\hline & Left & $28.14 \pm 5.90$ & $20.44 \pm 5.51$ & $24.29 \pm 6.84$ & $17.42 \pm 10.06$ & $\mathrm{~T}$ & 7.798 & $0.007^{* *}$ \\
\hline & Total average & $25.99 \pm 6.37$ & $21.52 \pm 5.90$ & $23.76 \pm 6.49$ & - & $L \times T$ & 4.043 & $0.050^{*}$ \\
\hline \multirow[t]{3}{*}{ DPSI } & Right & $28.23 \pm 7.17$ & $26.87 \pm 7.22$ & $27.55 \pm 7.09$ & $23.42 \pm 20.85$ & L & 0.432 & 0.514 \\
\hline & Left & $33.06 \pm 6.83$ & $24.46 \pm 6.43$ & $28.76 \pm 7.85$ & $17.36 \pm 10.09$ & $\mathrm{~T}$ & 7.248 & $0.010^{* *}$ \\
\hline & Total average & $30.65 \pm 7.30$ & $25.67 \pm 6.82$ & $28.16 \pm 7.44$ & - & $L \times T$ & 3.833 & 0.056 \\
\hline \multirow[t]{3}{*}{$\mathrm{RCOF}$} & Right & $0.74 \pm 0.39$ & $0.66 \pm 0.13$ & $0.70 \pm 0.29$ & $49.15 \pm 94.39$ & L & 0.039 & 0.844 \\
\hline & Left & $0.80 \pm 0.52$ & $0.64 \pm 0.22$ & $0.72 \pm 0.40$ & $24.51 \pm 35.78$ & $\mathrm{~T}$ & 1.778 & 0.188 \\
\hline & Total average & $0.77 \pm 0.45$ & $0.65 \pm 0.18$ & $0.71 \pm 0.34$ & - & $\mathrm{L} \times \mathrm{T}$ & 0.168 & 0.683 \\
\hline
\end{tabular}

Values are presented as mean \pm standard deviation.

N/BW, Newton/body weights; MLSI, medial-lateral stability index; APSI, anterior-posterior stability index; VSI, vertical stability index; DPSI, dynamics postural stability index; $R C O F$, required coefficient of friction; $L$, landing leg of the main effect; $T$, test of the main effect; $L \times T$, interaction.

${ }^{*} P<0.05 .{ }^{* *} P<0.01$.

limbs showed more symmetric pattern in post than that in before participation of Oreum trekking exercise program.

\section{DISCUSSION}

Nowadays, participants for climbing or walking for recreation and exercise rehabilitation show increasing trend gradually (Jensen et al., 2011). In the right of this trend, analysis range of this study focused on variables of postural stability and GRF as an effect of Oreum trekking exercise program.

PVF showed decreased value significantly after participation of Oreum trekking exercise program. That is, Oreum trekking exercise was performed on the various conditions of ground, of which stair and incline lane needs more muscle strength of lower leg and delays the supporting time of either leg (Kuster et al., 1995; Leroux et al., 1999). Whereas It was reported that magnitude of impact absorption and breaking force to the AP direction at the initial touch-down on descending lane showed increasing but decreasing trend in propulsive force (Lay et al., 2006). The environ- mental characteristics of Oreum trekking lane consist of lower various altitude, inclined lane, irregular condition of course than those of other mountains. Therefore it was considered that these conditions of Oreum trekking lane induced increased mechanism of impact absorption.

Dynamic stability index in all direction (frontal, sagittal, and horizontal) showed significant results after Oreum trekking exercise program. Dynamic stability index during locomotion is the control of the COM within a changing base of support and requires effective proactive and reactive recovery response strategies when exposed to perturbations (Franklin et al., 2003; Patla et al., 2000). Also it is considered that locomotion on the more unstable ground of Oreum trekking than those of level ground can induce improved sensory and motor control system and sense of regular position due to increased external sway motion of COM (Shumway-Cook and Horak, 1986).

RCOF did not show significant difference, but rather decreased after participation of Oreum trekking exercise program. That is, it was reported that modified and adapted strategy against slip- 
pery surface individually when confronted by slippery surface of ground during gait (Cham and Redfern, 2002; Myung and Smith, 1997). It was considered that characteristics of Oreum's surface consisting of lawn, sand, various soils and slippery prevention facilities can induce stable posture, confrontation strategies instantly.

Asymmetric index to postural stability and variables of GRF between bilateral limbs showed more stable symmetric pattern after participation of Oreum trekking exercise program. That is it was considered that Oreum trekking could induce the improved control ability of GRF in bilateral limbs and could facilitate stabilization of limb's joint related with motor performance by increasing the coordination between muscular-nervous system (Sannicandro et al., 2014). When consideration the above, Oreum trekking can be helpful exercise program for prevention of injuries (Sannicandro et al., 2014) and rehabilitation program for the handicapped with imbalanced function between bilateral limbs (Behm and Colado, 2012; Behm et al., 2010).

\section{CONFLICT OF INTEREST}

No potential conflict of interest relevant to this article was reported.

\section{ACKNOWLEDGMENTS}

This research was supported by the 2016 scientific promotion program funded by Jeju National University.

\section{REFERENCES}

Asaka T, Saito H, Yoshida N, Urakami D, Kamada K, Fukushima J. Relationship between the required coefficient of friction and gait initiation in young adults on a low friction floor. J Phys Ther Sci 2002;14:33-39.

Barber SD, Noyes FR, Mangine RE, McCloskey JW, Hartman W. Quantitative assessment of functional limitations in normal and anterior cruciate ligament-deficient knees. Clin Orthop Relat Res 1990;(255):204214.

Behm D, Colado JC. The effectiveness of resistance training using unstable surfaces and devices for rehabilitation. Int J Sports Phys Ther 2012;7:226-241.

Behm DG, Drinkwater EJ, Willardson JM, Cowley PM; Canadian Society for Exercise Physiology. Canadian Society for Exercise Physiology position stand: The use of instability to train the core in athletic and nonathletic conditioning. Appl Physiol Nutr Metab 2010;35:109-112.
Burnfield JM, Powers CM. The role of center of mass kinematics in predicting peak utilized coefficient of friction during walking. J Forensic Sci 2007;52:1328-1333.

Cham R, Redfern MS. Heel contact dynamics during slip events on level and inclined surfaces. Saf Sci 2002;40:559-576.

Choi WH, Shin WT, Shin W. Effect of obese women's exercise walking and interruption duration on the change of body compositions and leptin. Korean J Exerc Rehabil 2010;6:175-182.

Cooper RC, Prebeau-Menezes LM, Butcher MT, Bertram JE. Step length and required friction in walking. Gait Posture 2008;27:547-551.

Eisen TC, Danoff JV, Leone JE, Miller TA. The effects of multiaxial and uniaxial unstable surface balance training in college athletes. J Strength Cond Res 2010;24:1740-1745.

Franklin DW, Osu R, Burdet E, Kawato M, Milner TE. Adaptation to stable and unstable dynamics achieved by combined impedance control and inverse dynamics model. J Neurophysiol 2003;90:3270-3282.

Hoffman M, Payne VG. The effects of proprioceptive ankle disk training on healthy subjects. J Orthop Sports Phys Ther 1995;21:90-93.

Hyun SH, Lee AR, Ryew CC. Analysis of the ground reaction force parameters according to the change of position and weights of bag during downward stairs between dominant and non-dominant in upper \& lower limbs. Korean J Sport Biomech 2014; 24:43-50.

Jensen SB, Henriksen M, Aaboe J, Hansen L, Simonsen EB, Alkjaer T. Is it possible to reduce the knee joint compression force during level walking with hiking poles? Scand J Med Sci Sports 2011;21:e195-200.

Kim MH. The effect of rapid walking exercise on health related physical fitness and hs-CRP in older women adults with type II diabetes. J Exerc Rehabil 2007;3:24-30.

Knapik J, Harman E, Reynolds K. Load carriage using packs: a review of physiological, biomechanical and medical aspects. Appl Ergon 1996; 27:207-216

Kuster M, Sakurai S, Wood GA. Kinematic and kinetic comparison of downhill and level walking. Clin Biomech (Bristol, Avon) 1995;10:7984.

Lay AN, Hass CJ, Gregor RJ. The effects of sloped surfaces on locomotion: a kinematic and kinetic analysis. J Biomech 2006;39:1621-1628.

Lee BK, Kim TS. Effect of treadmill walking exercise after 8 weeks on the $\mathrm{DLCO}, \mathrm{Hb}$ and adjusted DLCOav/Hb in male collegian with smoking. J Exerc Rehabil 2010;6:199-207.

Leroux A, Fung J, Barbeau H. Adaptation of the walking pattern to uphill walking in normal and spinal-cord injured subjects. Exp Brain Res 1999;126:359-368.

Myung R, Smith JL. The effect of load carrying and floor contaminants on slip and fall parameters. Ergonomics 1997;40:235-246.

Patla AE, Winter DA, Ishac MG. Joint stability and not control of center of 
mass takes precedence during voluntary arm movements from standing posture. Arch Physiol Biochem 2000;108:211.

Sadeghi H, Allard P, Prince F, Labelle H. Symmetry and limb dominance in able-bodied gait: a review. Gait Posture 2000;12:34-45.

Sannicandro I, Cofano G, Rosa RA, Piccinno A. Balance training exercises decrease lower-limb strength asymmetry in young tennis players. J Sports Sci Med 2014;13:397-402.

Schilling BK, Falvo MJ, Karlage RE, Weiss LW, Lohnes CA, Chiu LZ. Effects of unstable surface training on measures of balance in older adults. J Strength Cond Res 2009;23:1211-1216.

Shumway-Cook A, Horak FB. Assessing the influence of sensory interac- tion of balance. Suggestion from the field. Phys Ther 1986;66:15481550.

Shumway-Cook A, Woollacott MH. Motor control: translating research into clinical practice. Philadelphia: Lippincott Williams \& Wilkins; 2007.

Taube W, Gruber M, Gollhofer A. Spinal and supraspinal adaptations associated with balance training and their functional relevance. Acta Physiol (Oxf) 2008;193:101-116.

Wikstrom EA, Tillman MD, Smith AN, Borsa PA. A new force-plate technology measure of dynamic postural stability: the dynamic postural stability index. J Athl Train 2005;40:305-309. 